\title{
Analisis Timbulan Dan Komposisi Sampah Untuk Potensi Reduksi Sampah Di Kelurahan Selamat
}

Widyawati ${ }^{1}$, Rinaldi ${ }^{2}$, dan Winny Laura C. ${ }^{3}$

${ }^{12,3}$ Teknik Lingkungan, Universitas Jambi Jambi, Indonesia

Email: widyawati.jbi97@gmail.com,winnylaura@yahoo.co.id

\section{Info Artikel}

Diterima: 4 Februari 2020

Disetujui: 15 Desember

2020

Dipublikasikan: 28

Desember 2020

\section{Alamat Korespondensi: \\ winnylaura@yahoo.co.id}

Copyright (C) 2020 Jurnal

Engineering

This work is licensed under the

Creative Commons

Attribution

International License (CC BY 4.0).

\begin{abstract}
Abstrak
Timbulan sampah akan meningkat seiring dengan pertambahan jumlah penduduk, sedangkan komposisi sampah mengalami perubahan setiap tahun akibat adanya perubahan pada pola hidup dan tingkat ekonomi masyarakat. Berbagai komponen sampah menyimpan potensi untuk dapat dimanfaatkan kembali atau diolah untuk menghasilkan produk baru non energi melalui proses recovery dan recycling. Hasil penelitian menunjukkan,, timbulan sampah yang dihasilkan di Kelurahan Selamat dalam satuan berat adalah 108,71 $\mathrm{kg} /$ hari atau dalam satuan volume $1,1186 \mathrm{~m}^{3} /$ hari. Komposisi sampah yang dihasilkan di Kelurahan Selamat terdiri dari, $65,57 \%$ sampah organik dan sampah anorganik 34,43 \% yang terdiri dari $12,55 \%$ sampah kertas, $0,13 \%$ sampah karet, $1,78 \%$ sampah tekstil, $17,08 \%$ sampah plastik, 0,56\% sampah kaca, 0,48\% sampah logam dan 1,85\% lain-lain. Potensi reduksi sampah di Kelurahan Selamat sebesar 56,16 kg/hari atau $51,66 \%$ dari total sampah. Potensi reduksi sampah berdasarkan komposisi jenis sampah dengan pengomposan 37,33\% dan daur ulang 14,33\%. Kesediaan masyarakat untuk mengolah sampah sendiri masih sangat rendah, ini disebabkan peran masyarakat untuk pengolahan sampah tidak sesuai. Pengelolaan yang dilakukan masyarakat hanya sebatas mengumpulkan sampah organik dan anorganik. Umumnya sampah dikumpulkan dan diangkut oleh petugas bahkan ada yang membakar secara langsung ditepi jalan atau perkarangan rumah disekitaran tempat tinggal.
\end{abstract}

Kata kunci: Timbulan \& Komposisi; Potensi Reduksi; Ketersediaan Masyarakat

\section{Abstract :}

The garbage production will increase as population growth, and the composition of garbage will lead to changes in lifestyle and social economy every year. Various waste 
components store the potential to reuse, process or process new energy products to produce through the recovery and recycling process. The results of the study showed that the Dalgu Team, the result of the weight unit survival rate, was calculated at $108.71 \mathrm{~kg} /$ day or a volume of $1,11686 \mathrm{~m} 3 / \mathrm{h}$. The waste composition produced only under Guha consists of $65.7 \%$ of organic waste, $34.4 .3 \%$ of organic waste, $0.13 \%$ of rubber waste, $17.08 \%$ of textile waste, $0.5 \%$ of plastic waste, and $0.48 \%$ of impurities. The amount of waste to be celebrated is $56,16 \mathrm{~kg} /$ day or $51.66 \%$ of total waste. The potential for waste deposition is based on the composition of recyclable waste paper of $37.33 \%$ and $14.333 \%$. The supply of communities to dispose of garbage is still extremely low, because the society of garbage disposal does not work properly. The officials that the public has been doing nothing but collecting organic and inorganic waste. Usually, some people burned garbage directly on the roads around the house or around the house.

Keywords: waste production; social participation 


\section{Pendahuluan}

Sampah merupakan salah satu masalah yang perlu mendapat perhatian karena sampah umumnya selalu meningkat dari tahun ke tahun seiring dengan laju pertumbuhan penduduk. Kelurahan Selamat merupakan salah satu kelurahan yang terletak di Kecamatan Danau Sipin, Kota Jambi. Kondisi eksisting Kelurahan Selamat adalah permukiman padat dan terdapat pertokoan, sekolah, pasar dan kantor. Masalah persampahan di Kelurahan Selamat adalah pengelolaan sampah seperti halnya masih bertumpu pada pola lama, yaitu sampah dikumpulkan dari sumbernya, diangkut ke TPS (Tempat Penampungan Sementara)/Bak Sampah, dan dibuang ke TPA (Tempat Pemrosesan Akhir) dan tidak adanya tempat pengolahan sampah sebelum menuju ke TPA maka pengelolaan sampah dapat dipertahankan dengan pembentukan program keterlibatan masyarakat untuk melakukan pengurangan sampah, dimanfaatkan kembali, dan daur ulang (reduce, reuse, and recycle). Berbagai komponen sampah menyimpan potensi untuk dapat dimanfaatkan kembali atau diolah untuk menghasilkan produk baru non energi melalui proses recovery dan recycling. Oleh sebab itu, dalam penelitian ini akan dilakukan sampling sampah di Kelurahan Selamat untuk dapat mengetahui data timbulan dan komposisi sampah, menganalisis potensi reduksi sampah dan menganalisis kesediaan masyarakat dalam mengolah sampahnya sendiri

\section{Metode Penelitian}

Dalam penelitian ini perhitungan jumlah sampel, cara pengambilan dan pengukuran sampel timbulan sampah dilakukan berdasarkan SNI 19-3964-1994 tentang Metode Pengambilan danPengukuran Contoh Timbulan dan Komposisi Sampah Perkotaan. Metode yang digunakan pada penelitian ini adalah kuantitatif. Dalam penelitian ini, akan dilakukan pengukuran untuk menghitung timbulan dan komposisi sampah, kemudian data kuesioner akan diolah dengan metode kualitatif kemudian dilakukan analisis sehingga dapat diambil suatu keputusan tentang bagaimana karakteristik sampah pada wilayah studi dengan komposisi sampah yang tersedia dan berapa besar potensi reduksi sampah pada wilayah studi.

\section{Hasil Penelitian dan Pembahasan}

Berdasarkan data hasil pengukuran timbulan sampah dari berbagai jenis sumber yang diteliti adalah sebagai berikut:

Tabel. 1 Data Berat dan Volume

\begin{tabular}{lcl}
\hline Sumber Sampah & \multicolumn{1}{c}{$\begin{array}{c}\text { Berat Timbulan } \\
\text { (kg/orang) }\end{array}$} & $\begin{array}{c}\text { Volume Timbulan } \\
\text { (liter/orang) }\end{array}$ \\
\hline Permukiman & 0,30 & 2,45 \\
Pertokoan & 0,09 & 2,46 \\
Pasar & 2,74 & 20,60 \\
Perkantoran & 0,05 & 0,85 \\
Sekolah & 0,01 & 0,13 \\
\hline
\end{tabular}

Pada Tabel. 1 data hasil penelitian pengukuran sampah terlihat bahwa sampah pasar dan permukiman memiliki nilai timbulan per kapita yang besar. Dilihat dari luas wilayah permukiman $71 \%$ dari keseluruhan luas wilayah Kelurahan Selamat maka beban timbulan yang dihasilkan oleh sampah permukiman menjadi yang paling besar. Untuk sampah pasar memiliki nilai timbulan terbesar disebabkan oleh aktivitas perdagangan yang tinggi dilakukan di pasar dan konsisten hamper sama besar setiap harinya.

\section{A. Komposisi Sampah}


Volume 2 Nomor 2, Januari 2020

Berdasarkan pengukuran langsung di lapangan diperoleh data komposisi yang diolah menjadi presentasi komposisi timbulan sebagai berikut:

Tabel. 2 Data Persentase Komposisi Sampah

\begin{tabular}{|c|c|c|c|c|c|c|c|c|c|c|c|c|}
\hline \multirow[t]{2}{*}{ No } & \multicolumn{2}{|c|}{ Komposisi Sanpah } & \multicolumn{2}{|c|}{ Permukiman } & \multicolumn{2}{|c|}{ Pertokoan } & \multicolumn{2}{|l|}{ Pasar } & \multicolumn{2}{|c|}{ Kantor } & \multicolumn{2}{|c|}{ Sekolah } \\
\hline & Primer & Sekunder & Kg & $\%$ & Kg & $\%$ & Kg & $\%$ & $\mathbf{K g}$ & $\%$ & $\mathbf{K g}$ & $\%$ \\
\hline 1 & Organik & Total & 145,7 & 68,4 & 55,3 & 55,2 & 302,9 & 94,1 & 21,8 & 41,8 & 44,6 & 24,5 \\
\hline \multirow[t]{4}{*}{2} & Kertas & $\begin{array}{l}\text { Kardus, Kertas, } \\
\text { Majalah, } \\
\text { Koran \& Tisu }\end{array}$ & 11,4 & 5,3 & 6,7 & 6,7 & 1,8 & 0,5 & 6,4 & 12,3 & 31,6 & 17,3 \\
\hline & & $\begin{array}{l}\text { Kemasan } \\
\text { Tetrapak }\end{array}$ & 2,2 & 1,0 & 5,4 & 5,4 & 1,6 & 0,5 & 3,6 & 6,9 & 9,0 & 4,9 \\
\hline & & Lainnya & 4,0 & 1,9 & 8,2 & 8,1 & 0,7 & 0,2 & 4,3 & 8,3 & 12,4 & 6,8 \\
\hline & & Total & 17,6 & 8,2 & 20,3 & 20,2 & 4,1 & 1,3 & 14,3 & 27,4 & 53,0 & 29,1 \\
\hline 3 & Karet & Total & 0,3 & 0,1 & 0,1 & 0,1 & $\mathbf{0 , 0}$ & $\mathbf{0 , 0}$ & 0,5 & 1,0 & 0,2 & 0,1 \\
\hline \multirow[t]{3}{*}{4} & Tekstil & Kain & 1,1 & 0,5 & 0,8 & 0,8 & 0,0 & 0,0 & 0,4 & 0,8 & 1,9 & 1,0 \\
\hline & & Diaper/pampers & 10,2 & 4,8 & 0,0 & 0,0 & 0,0 & 0,0 & 0,9 & 1,6 & 0,3 & 0,2 \\
\hline & & Total & 11,2 & 5,3 & 0,8 & 0,8 & $\mathbf{0 , 0}$ & $\mathbf{0 , 0}$ & 1,3 & 2,4 & 2,2 & 1,2 \\
\hline \multirow[t]{7}{*}{5} & Plastik & HD & 6,9 & 3,2 & 1,0 & 1,0 & 6,7 & 2,1 & 2,7 & 5,1 & 12,6 & 6,9 \\
\hline & & HDPE & 0,0 & 0,0 & 0,0 & 0,0 & 0,5 & 0,2 & 0,0 & 0,0 & 0,0 & 0,0 \\
\hline & & PS & 13,6 & 6,4 & 13,4 & 13,4 & 0,0 & 0,0 & 0,1 & 0,2 & 5,6 & 3,0 \\
\hline & & PETE/PET & 1,4 & 0,7 & 5,2 & 5,2 & 2,5 & 0,8 & 5,2 & 9,9 & 12,7 & 7,0 \\
\hline & & Plastik lain & 1,1 & 0,5 & 1,6 & 1,6 & 4,3 & 1,3 & 4,1 & 7,9 & 46,9 & 25,8 \\
\hline & & Karung Plastik & 0,0 & 0,0 & 0,0 & 0,0 & 0,4 & 0,1 & 0,0 & 0,0 & 0,0 & 0,0 \\
\hline & & Total & 23,1 & 10,8 & 21,3 & 21,2 & 14,5 & 4,5 & 12,1 & 23,2 & 77,7 & 42,7 \\
\hline 6 & Kaca & Total & 2,0 & 0,9 & 1,0 & 1,0 & 0,4 & 0,1 & 0,5 & 1,0 & 1,0 & 0,6 \\
\hline \multirow[t]{4}{*}{7} & Logam & Kaleng Besi & 0,0 & 0,0 & 0,0 & 0,0 & 0,0 & 0,0 & 0,0 & 0,0 & 0,0 & 0,0 \\
\hline & & Alumunium can & 0,5 & 0,2 & 0,5 & 0,5 & 0,0 & 0,0 & 0,4 & 0,8 & 1,8 & 1,0 \\
\hline & & Logam lain & 0,4 & 0,2 & 0,1 & 0,1 & 0,0 & 0,0 & 0,0 & 0,0 & 0,0 & 0,0 \\
\hline & & Total & 0,9 & 0,4 & 0,5 & 0,5 & $\mathbf{0 , 0}$ & $\mathbf{0 , 0}$ & 0,4 & 0,8 & 1,8 & 1,0 \\
\hline 8 & $\begin{array}{l}\text { Lain- } \\
\text { lain }\end{array}$ & Total & 12,4 & 5,8 & 0,9 & 0,9 & $\mathbf{0 , 0}$ & 0,0 & 1,2 & 2,4 & 1,6 & 0,9 \\
\hline \multicolumn{3}{|c|}{ Total Seluruhnya } & 213,1 & 100,0 & 100,2 & 100,0 & 321,9 & 100,0 & 52,0 & 100,0 & 182,0 & 100,0 \\
\hline
\end{tabular}

B. Analisis Potensi Reduksi Sampah

Potensi reduksi sampah dapat ditetapkan berdasarkan material balance, dengan memperhitungkan recovery factor setiap komponen sampah. Analisis material balance dilakukan berdasarkan nilai berat timbulan sampah di Kelurahan Selamat dan nilai recovery factor sehingga dapat diketahui potensi reduksi sampah di Kelurahan Selamat.

Tabel. 3 Material balance Sampah Dengan Memperhitungkan Potensi Reduksi

\begin{tabular}{|c|c|c|c|c|c|c|c|c|c|}
\hline \multirow{2}{*}{ No } & \multirow{2}{*}{ Komponen } & \multirow{2}{*}{$\begin{array}{c}\text { Komposisi } \\
(\%)\end{array}$} & \multirow{2}{*}{$\begin{array}{l}\text { Timbulan } \\
\text { (Kg/hari) }\end{array}$} & \multirow{2}{*}{$\begin{array}{c}\text { Komposting } \\
(\%)\end{array}$} & \multirow{2}{*}{$\begin{array}{c}\text { Daur Ulang } \\
(\%)\end{array}$} & \multicolumn{2}{|c|}{ Reduksi } & \multicolumn{2}{|c|}{ Sisa Timbulan } \\
\hline & & & & & & (Kg/hari) & $\%$ & (Kg/hari) & $\%$ \\
\hline I & Sampah Kering & & & & & & & & \\
\hline 1 & Kertas & 12,55 & 13,64 & & 40,00 & 5,46 & 5,02 & 8,18 & 7,53 \\
\hline 2 & Karet & 0,13 & 0,14 & & & & & 1,13 & 0,13 \\
\hline 3 & Tekstil & 1,78 & 1,93 & & & & & 1,93 & 1,78 \\
\hline 4 & Plastik & 17,08 & 18,57 & & 50,00 & 9,28 & 8,54 & 9,28 & 8,54 \\
\hline
\end{tabular}




\begin{tabular}{|c|c|c|c|c|c|c|c|c|c|}
\hline 5 & Kaca & 0,56 & 0,61 & & 65,00 & 0,40 & 0,37 & 0,21 & 0,20 \\
\hline \multirow[t]{2}{*}{6} & Logam & 0,48 & 0,52 & & 85,00 & 0,44 & 0,41 & 0,08 & 0,07 \\
\hline & Sub Total & & & & & 15,58 & 14,33 & 20,82 & 18,24 \\
\hline \multirow[t]{2}{*}{ II } & Sampah basah & 65,57 & 71,29 & 56,93 & & 40,58 & 37,33 & 30,70 & 28,24 \\
\hline & Sub Total & & & & & 40,58 & 37,33 & 30,70 & 28,24 \\
\hline \multirow[t]{3}{*}{ III } & Lain-lain & 1,85 & 2,01 & & & & & 2,01 & 1,85 \\
\hline & Sub Total & & & & & & & 2,01 & 1,85 \\
\hline & TOTAL & 100,00 & 108,71 & & & 56,16 & 51,66 & 53,54 & 48,34 \\
\hline
\end{tabular}

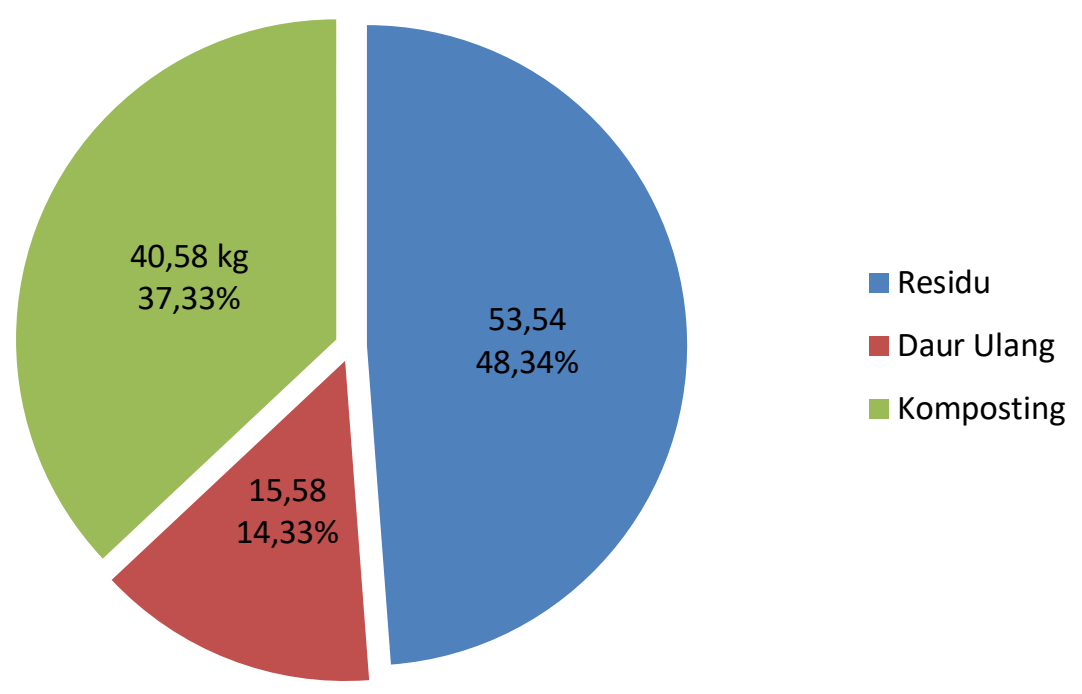

Gambar. 1 Potensi Reduksi Sampah dengan Komposting dan Daur Ulang

Dari Gambar. 1 potensi reduksi sampah di Kelurahan Selamat dengan metode daur ulang/pemilahan menghasilkan bahan daur ulang sebesar 14,33\% dengan sisa timbulan 18,24\%. Sedangkan metode komposting akan menghasilkan 37,33\% dan sisa timbulan 28,24\%. Sisa timbulan yang dibuang ke TPA adalah 48,34\%. Sehingga dengan metode daur ulang dan komposting dapat mengurangi volume sampah yang dibuang ke TPA sebesar 51,66\% atau $0.06 \mathrm{~m}^{3}$.

\section{Data Responden}

Pada penelitian ini, kuesioner dijadikan sebagai pengumpulan data untuk dapat mengetahui ketersediaan masyarakat untuk mengolah sampah sendiri di Kelurahan Selamat. Jumlah responden di Kelurahan Selamat ini adalah sebanyak 50 orang. Pendidikan terakhir yang dimiliki responden dapat dilihat pada diagram batang dibawah ini.

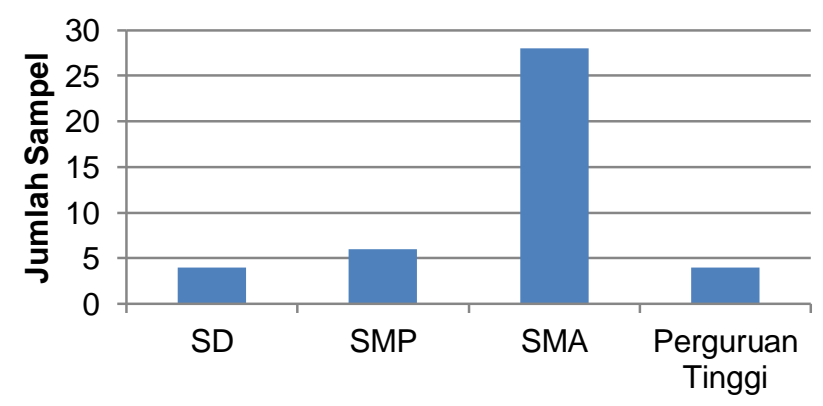

Gambar. 2 Tingkat Pendidikan Responden (Hasil Olahan, 2018) 
Jenis pekerjaan yang dimiliki responden terdiri dari tidak bekerja, PNS, TNI, ABRI, pegawai swasta, wiraswasta, petani, buruh, dan pensiun.

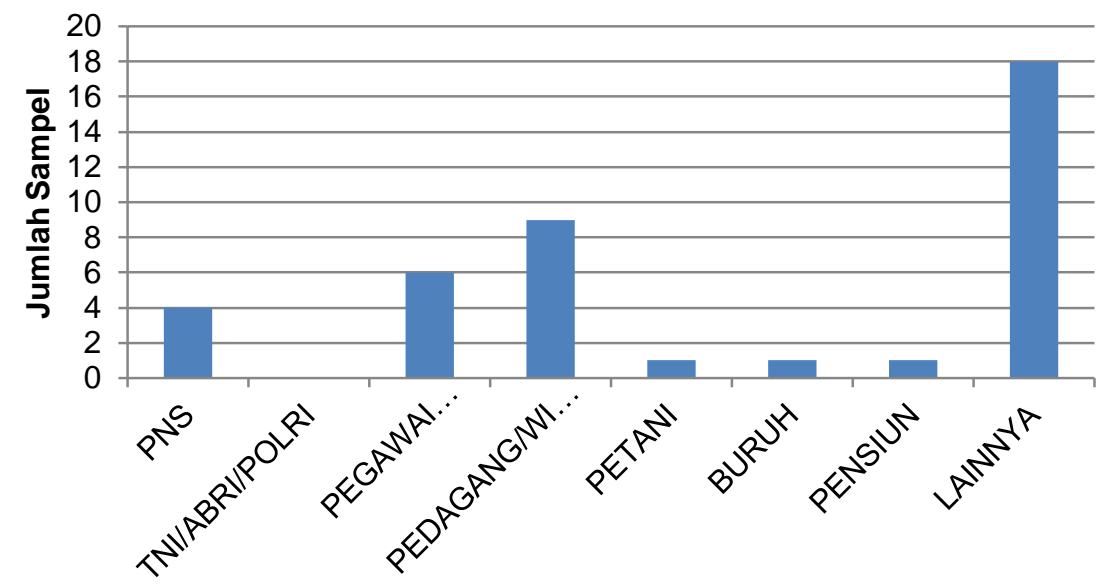

Gambar. 3 Pekerjaan Responden

(Hasil Olahan, 2018)

Dari sisi ekonomi, total pendapatan dari rumah sampel diwakilkan oleh 1 responden yang akan menjawab pertanyaan menenai hal ini. Jumlah pendapatan dikelompokkan memiliki kisaran per bulan kurang dari Rp. 500.000, Rp. 500.000 1.000.000, Rp. 1.000.000 - 3.000.000, Rp. 3.000.000 - 5.000.000, dan lebih dari Rp. 5.000.000. Gambar berikut akan menunjukkan pendapatan responden.

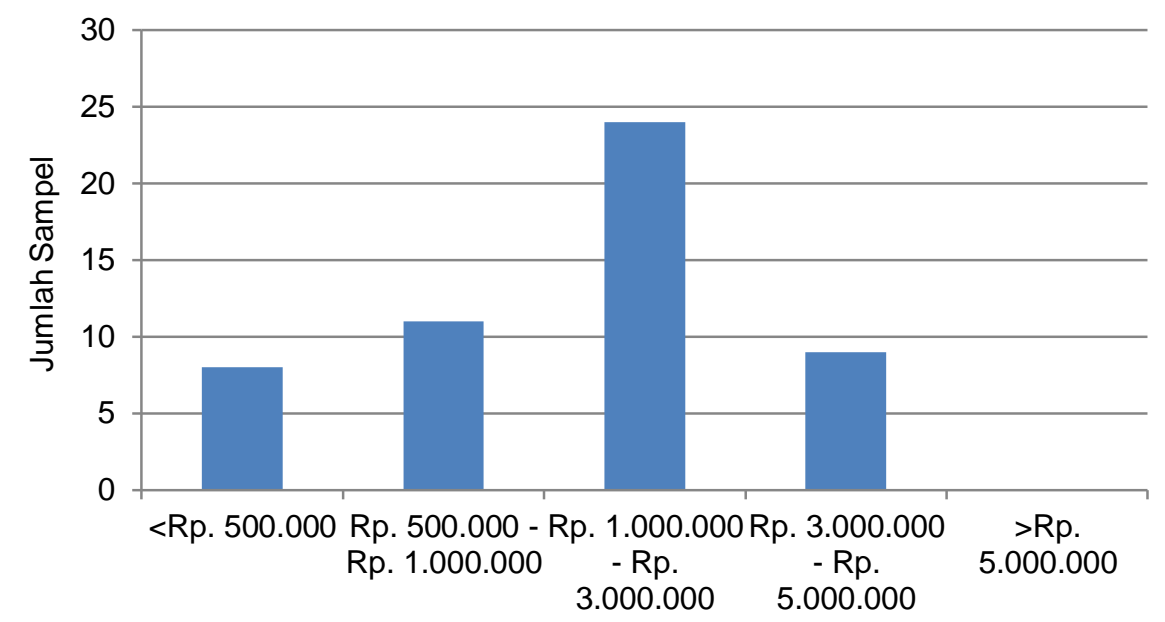

Gambar. 4 Total Pendapatan Rumah Responden

(Hasil Olahan, 2018)

Selanjutnya, pengetahuan responden mengenai pengertian sampah itu adalah suatu bahan yang terbuang atau dibuang dari sumber hasil aktivitas manusia maupun proses alam yang memiliki nilai ekonomis. 42 orang menjawab "ya" dan 8 orang menjawab "tidak". Pengetahuan mengenai pengertian sampah ini tidak tergantung dengan pendidikan setiap responden.

Pengelolaan sampah yang baik penting sekali untuk diketahui seluruh masyarakat. Perilaku yang dilakukan oleh masyarakat akan membantu pemerintah dalam menerapkan sistem pengelolaan sampah. Jawaban responden mengenai pertanyaan tentang dilakukan pemisahan sampah basah dan kering dirumah responden. Dari 50 responden 50\% sampel menjawab perlu dilakukan pemisahan sampah kering dan basah karena beberapa sampel berpendapat agar sampah yang masih memiliki nilai harga bisa dijual atau dimanfaatkan kembali. Dan $24 \%$ 
menjawab tidak dan $24 \%$ menjawab tidak tau. Apabila responden menjawab "ya" maka tentu saja informasi yang didapatkan tersebut tidak begitu saja datang, akan tetapi dapat bersumber dari sesuatu yang membuat responden mengenal pengelolaan sampah.

Berikutnya adalah prilaku masyarakat apakah sudah melakukan pemisahan sampah yang mudah membusuk atau tidak dirumah responden. Jawaban didominasi dengan tidak melakukan pemisahan sebesar $68 \%$ dari total responden karna menurut mereka ribet dan tidak memiliki waktu dan 32\% menjawab "iya" karna menurut mereka itu salah satu bentuk prilaku dan partisipasi untuk mengolah sampah dilingkungan sendiri.

Sampah yang telah dikumpulkan di rumah masing-masing, harus dilakukan tindakan selanjutnya. Pada kuisioner terdapat pertanyaan mengenai hal ini dengan pilihan jawaban seperti dibakar, dibuang ke sungai, digeletakkan di lahan kosong, ditumbun, diangkut oleh petugas sampah, dibuat kompos, atau dijual (untuk sampah anorganik). Untuk perlakuan sampah di rumah masing-masing tidak ditemukan responden yang membuang sampah ke sungai, dibuat kompos dan dijual (untuk sampah anorganik). Karna 60\% dari jawaban responden sampah dirumah langsung diangkut oleh petugas. Berikut adalah jawaban responden.

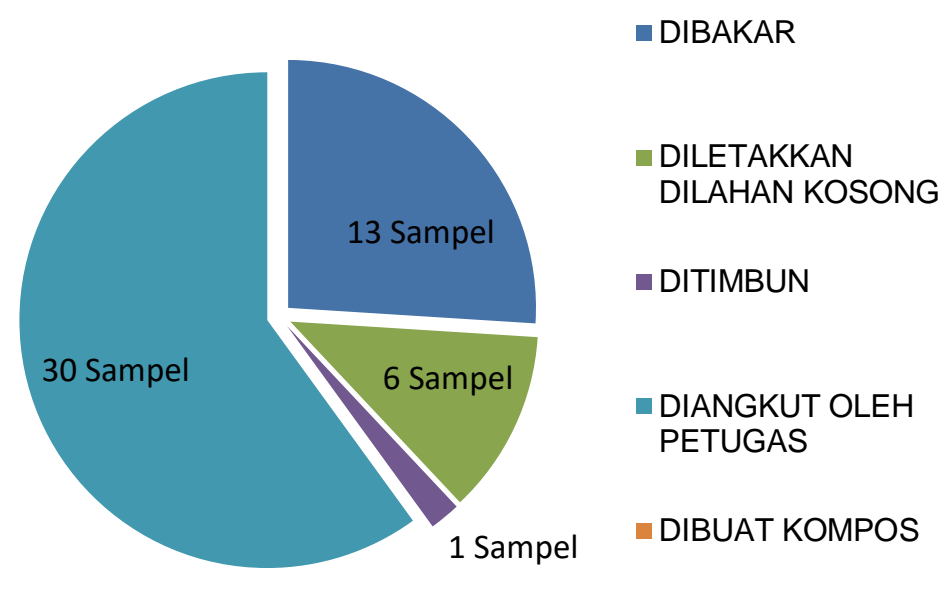

Gambar. 5 Perlakuan terhadap Sampah Responden

(Hasil Olahan, 2018)

Masyarakat adalah elemen penting yang akan memepengaruhi kesuksesan pengelolaan sampah. Minat masyarakat untuk mengelola sampah dimulai dari diri sendiri akan tercemin pada jawaban responden yang meskipun rata-rata responden tidak melakukan pemisahan sampah namun jika diadakan program pengelolaan sampah dilingkungannya dari 50 responden $96 \%$ orang menjawab ya dan $4 \%$ menjawab tidak karena mereka berpendapat bahwa selama mereka tinggal di lingkungan itu rata-rata masyarakat tidak begitu perduli dengan lingkungan disekitarnya, jika diadakan program tersebut belum tentu akan terus berjalan. Ini terbukti dari jawaban mereka yang masih memilih pengelolaan dilakukan secara terpusat dibandingkan secara individu, terlihat pada Gambar. 6 dimana 72\% milih secara terpusat dan 28\% secara individu karena mereka beralasan agar lebih mudah. 


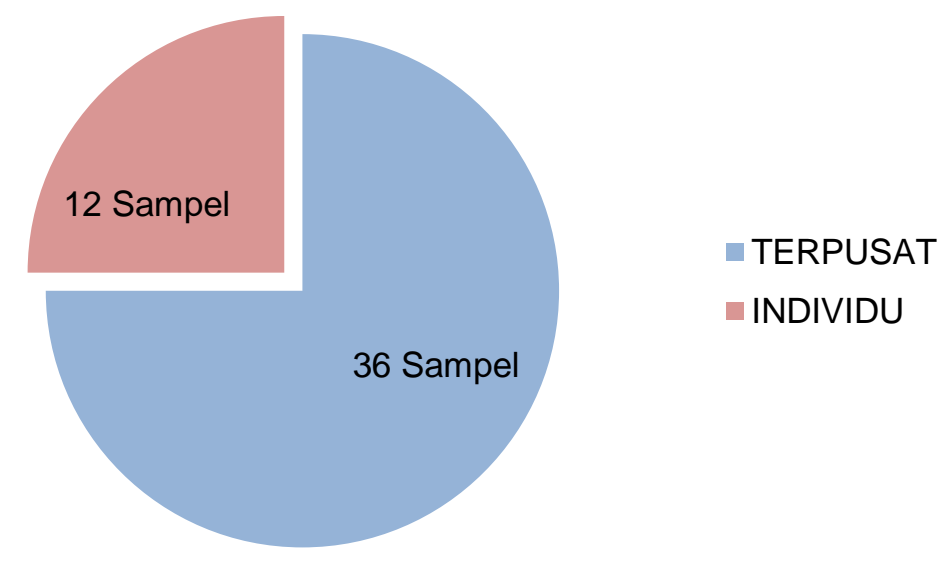

Gambar. 6 Pengolahan Sampah dilingkungan Responden (Hasil Olahan, 2018)

Masyarakat adalah elemen penting yang akan memepengaruhi kesuksesan pengelolaan sampah. Minat masyarakat untuk mengelola sampah dimulai dari diri sendiri hal ini juga dapat dilihat pada jawaban apakah mau membuat kompos 54\% dari total responden menjawab tidak karena mereka beralasan tidak memiliki waktu dan juga sampah organik itu kotor. Namun pada pertanyaan mengumpulkan sampah anorganik unuk didaur ulang didominasi menjawab ya sebesar 60\% dari total responden karena responden beralasan lebih mudah dipisahkan dan bisa dijual dan juga perlakuan sampah anorganik ini tidak sesulit sampah organik.

\section{KESIMPULAN}

Berdasarkan pada tujuan dilakukan penelitian ini, maka dari hasil penelitian dan pembahasan dapat diambil beberapa kesimpulan yaitu Jumlah timbulan sampah yang dihasilkan di Kelurahan Selamat dalam satuan berat adalah 108,71 kg/hari atau dalam satuan volume $1,1186 \mathrm{~m}^{3}$ /hari. Jumlah komposisi sampah yang dihasilkan di Kelurahan Selamat terdiri dari, 65,57\% sampah organik dan sampah anorganik 34,43 \% yang terdiri dari $12,55 \%$ sampah kertas, $0,13 \%$ sampah karet, $1,78 \%$ sampah tekstil, $17,08 \%$ sampah plastik, 0,56\% sampah kaca, 0,48\% sampah logam dan 1,85\% lain-lain. Dengan menggunakan nilai-nilai recovery factor, besarnya jumlah sampah kering yang dapat didaur ulang di Kelurahan Selamat adalah sebagai berikut: sampah kertas 5,46 kg/hari, sampah plastik 9,28 kg/hari, sampah kaca 0,40 kg/hari, dan sampah logam $0,44 \mathrm{~kg} /$ hari. Jumlah total reduksi sampah di Kelurahan Selamat berdasarkan jenis-jenis sampah tersebut adalah 15,58 kg/hari. Sedangkan sampah basah/organik sebesar 40,58 kg/hari. Kesediaan masyarakat untuk mengolah sampah sendiri masih sangat rendah, ini disebabkan peran masyarakat untuk pengolahan sampah tidak sesuai. Pengelolaan yang dilakukan masyarakat hanya sebatas mengumpulkan sampah organik dan anorganik. Umumnya sampah dikumpulkan dan diangkut oleh petugas bahkan ada yang membakar secara langsung ditepi jalan atau perkarangan rumah disekitaran tempat tinggal. Faktor seperti usia, tingkat pendidikan, jenis pekerjaan dan jumlah penghasilan tidak mempunyai pengaruh secara nyata terhadap keinginan masyarakat untuk mengolah sampah sendiri. 


\section{REFERENSI}

[1] Achmad Zubair, Haeruddin (2012). Studi Potensi Daur Ulang Sampah Di TPA Tamanggapa Kota Makassar. Jurnal. Jurusan Teknik Sipil. Fakultas Teknik. UNHAS. Makassar.

[2] Anissa Yanuarina Putri, Cindy Rianti Priadi, Gabriel S. B. Andari (2013). Pengaruh Pengelolaan Limbah Padat Kertas dan Plastik. Jurnal. Program Studi Teknik Lingkungan. Fakultas Teknik. Universitas Indonesia.

[3] Azwar, Asrul. (1990). Pengantar Ilmu Kesehatan Lingkungan. Jakarta: Mutiara Sumber Widya.

[4] Badan Perencanaan Pembangunan Daerah Provinsi Jambi. 2016. Profil Kota Jambi. Sub Bidang Data dan Statistik dan Pelaporan.

[5] Badan Pusat Statistik Provinsi Jambi (2012). Profil Kecamatan Telanaipura. Jambi: Badan Pusat Statistik Provinsi Jambi

[6] Badan Pusat Statistik. 2017. Kota Jambi Dalam Angka 2017. BPS Kota Jambi: Jambi.

[7] Damanhuri, E., \& Padmi, T. (2010). Diktat Kuliah TL - 3104. Bandung: Institut Teknologi Bandung.

[8] Darmasetiawan Martin. Ir. MSi (2004). Sampah Dan Sistem Pengelolaannya. Jakarta:Ekamitra Engineering.Halaman I-8.

[9] Departemen PekerjaanUmum. 2010. Pedoman Umum 3R Berbasis Masyarakat di Kawasan Permukiman.

[10] Devi, Safitri A., H \& Welly, Herumurti. (2017). Laju Timbulan dan Komposisi Sampah Rumah Tangga di Kecamatan Sukolilo Surabaya. Jurnal. Fakultas Teknik Sipil dan Perencanaan. Institute Teknologi Sepuluh Nopember (ITS).

[11] Kantor Lurah Selamat (2017). Instrumen Penelitian Monografi Kelurahan Selamat. Jambi: Kantor Lurah Selamat.

[12] Kantor Lurah Selamat (2017). Profil Kelurahan Selamat. Jambi: Kantor Lurah Selamat.

[13] Maria Winda Anggreni. (2012). Pengelolaan Limbah Padat Sebagai Bagian Penerapan Konsep Green Building. Studi Kasus: Kantor Pusat PT. Pertamina, Jakarta. Skripsi. Fakultas Teknik. Universitas Indonesia.

[14] Nitikesari, Putu Ening. (2005). Analisis Tingkat Partisipasi Masyarakat dalam Penanganan Sampah Secara Mandiri di Kota Denpasar. Tesis Magister Program Pascasarjana Universitas Udayana, Denpasar.

[15] P.R. Ari Setiadi,J.B.Widiadi, Dewi Dwirianti. (2005). Kajian Potensi Reduksi Sampah dan Sistem Pengumpulan Sampah Di Kecamatan Rembang dan Kecamatan Lasem KabupatenRembang. Jurnal. Program Magister Teknik Lingkungan. ITS Sukolilo Surabaya.

[16] Rury Fuadhilah. 2012. Timbulandan Komposisi Sampah Sebagai Dasar Perancangan Teknis Operasional Persampahan Pada Kecamatan Serpong, Serpong Utara, dan Setu Sebagai Daerah IndustriDi Kota Tanggerang Selatan.Skripsi. Fakultas Teknik. Universitas Indonesia.

[17] SNI 19-2454-2002 tentang Tata Cara Teknik Operasional Pengelolaan Sampah Perkotaan. Badan Standarisasi Nasional.

[18] SNI 19-3964-1994 tentang Metode Pengambilan dan Pengukuran Contoh Timbulan dan Komposisi Sampah Perkotaan. 
[19] SNI 19-3983-1995 Tentang Spesifikasi Timbulan Sampah Untuk Kota Kecil dan Sedang di Indonesi. Badan Standarisasi Nasional.

[20] Suryati, Teti. (2009). Bijak \& Cerdas Mengolah Sampah Membuat Kompos dari Sampah Rumah Tangga. Jakarta: Agromedia Pustaka.

[21] Tchobanoglous, G, Theisen, H, Vigil, S. (1993). Integrated Solid Waste Management : Engineering Principles and Management Issues. Mc. GrawHill, Inc: New York.

[22] Tchobanoglous, G, Theisen, H, Vigil s.a. (2002). Handbook of Solid Waste Management. New York: Mc. Graw-Hill.

[23] Tri Astuti Ramandhani. 2011. Analisis Timbulan dan Komposisi Sampah Rumah Tangga Di Kelurahan Mekar Jaya (Depok) Dihubungkan Dengan Tigkat Pendapatan-Pendidikan-Pengetahuan-Sikap-Perilaku Masyarakat. Skripsi. Fakultas Teknik. Universitas Indonesia.

[24] Undang-undang Nomor 18 Tahun 2008 Tentang Pengelolaan Sampah. 